\title{
PENENTUAN PRIORITAS PERBAIKAN GEDUNG MENGGUNAKAN METODE AHP DARI SUDUT PANDANG TENANT
}

\author{
Stefanus Santosa ${ }^{1, *)}$, Mochammad Tri Rochadi ${ }^{1)}$, Suroso ${ }^{1)}$, Suwarto ${ }^{1)}$, \\ Mawardi $^{1)}$ \\ 1) Jurusan Teknik Sipil Politeknik Negeri Semarang \\ Jl. Prof H. Sudarto, S.H. Tembalang Semarang 50275 \\ ${ }^{*}$ Email: stefanus.st@gmail.com
}

\begin{abstract}
Bangunan mall adalah pusat perbelanjaan yang secara arsitektur berupa bangunan tertutup dengan suhu yang diatur dan memiliki jalur yang teratur. Infrastruktur bangunan mall terdiri dari beberapa tenant yang menawarkan berbagai macam kebutuhan masyarakat serta adanya atrium dalam mall yang berfungsi sebagai tempat pameran. Tujuan dari penelitian ini adalah mengetahui urutan prioritas dan kondisi bangunan mall, yang berguna sebagai acuan dalam kegiatan perbaikan yang berimbas pada kepuasan tenant. Permasalahan kepuasan tenant dapat diakibatkan dari berbagai faktor salah satunya, yaitu terkait fasilitas, perbaikan gedung dan penanganannya yang dikhawatirkan dapat mempengaruhi produktivitas. Data primer pada penelitian ini diperoleh dengan cara pengamatan langsung di lokasi penelitian, dan menyebarkan form kuisioner kepada responden yang terkait. Data sekunder diperoleh dari data penelitian terdahulu, peraturan yang berlaku, dan pedoman bangunan gedung. Penelitian ini menggunakan metode Analytical Hierarchy Process (AHP), untuk menentukan bobot komponen yang diperoleh dari hasil penilaian kepentingan komponen bangunan, oleh masingmasing responden. Hasil analisis menunjukkan bahwa faktor pertimbangan utama perbaikan gedung peringkat pertama adalah faktor kenyamanan dengan nilai prioritas 21,299\%, peringkat kedua faktor keselamatan dengan nilai prioritas $18,343 \%$, peringkat ketiga faktor danal biaya yang terbatas dengan nilai prioritas 16,192\%. Berdasarkan model hierarki yang telah disusun, maka dapat ditemukan Model Prioritas Pengambilan Keputusan Perbaikan Gedung khususnya Mall dengan mempertimbangkan faktor kenyamanan, kesehatan, keselamatan, kemudahan akses, danal biaya yang terbatas, petugas yang terbatas, dan waktu yang terbatas (deadline).
\end{abstract}

Kata kunci : perbaikan gedung, analytical hierarchy process (AHP), mall.

\section{PENDAHULUAN}

Mall adalah pusat perbelanjaan yang berintikan satu atau beberapa departement store besar sebagai daya tarik dari retail-retail kecil dan rumah makan dengan tipologi bangunan seperti toko yang menghadap ke koridor utama mall atau pedestrian yang merupakan unsur utama dari sebuah pusat perbelanjaan (mall), dengan fungsi sebagai sirkulasi dan sebagai ruang komunal bagi terselenggaranya interaksi antara 
pengunjung dan pedagang (Maitland, 1987).

Paragon Mall Semarang merupakan pusat perbelanjaan berkonsep Lifestyle and Entertainment Mall yang didirikan oleh investor Poo Sun Kuok. Paragon Mall Semarang terletak di Jalan Pemuda No.118 Semarang. Paragon Mall memiliki berbagai tenant (penyewa) dalam negeri dan luar negeri. Tenant tersebar di setiap lantai mall.

Sebagai gedung komersil dengan luas pertokoan $120.000 \mathrm{~m}^{2}$ dan area parkir yang luas dengan kapasitas 3.500 mobil, Paragon Mall Semarang mempunyai manajemen pemeliharaan dan perbaikan terhadap tenant. Seiring dengan penggunaan dan produktivitas tenant, muncul masalah berupa kerusakan pada fasilitas dan komponen bangunan yang menyebabkan produktivitas menurun.

Menurut Sinchaloenman dan Ngamyan faktor-faktor yang mempengaruhi kepuasan tenant adalah centre management performance, responsive behavior, service quality, cooperation, empowerment, trust, dan renew (Sinchaloenman, 2013).

Kendala yang dihadapi Paragon Mall Semarang dalam melaksanakan perbaikan adalah biaya dan tersedianya bahan siap pakai jika terjadi kerusakan. Hal ini disebabkan pengajuan biaya perbaikan memerlukan waktu yang lama sampai proses disetujui oleh General Manager. Untuk itu Tim Property dan Tim Engineering mengatasinya dengan memakai bahan yang ada atau memanfaatkan bahan yang masih bisa dipakai ulang.
Penilaian kondisi bangunan pada suatu waktu dapat dilakukan dengan menetapkan index kondisi bangunan yang merupakan penggabungan dua atau lebih nilai kondisi komponen dikalikan dengan bobot komponen masing-masing. Kerusakan komponen bangunan menjadi masalah yang serius dalam mall, karena akan mengganggu produktivitas dan operasional tenant yang bersangkutan. Oleh karena itu, perbaikan komponen gedung sangat diperlukan agar tetap laik fungsi.

Penentuan prioritas merupakan hal yang kompleks dan rumit karena melibatkan banyak aspek seperti kenyamanan, kesehatan, keselamatan, kemudahan akses, biaya terbatas, petugas terbatas, atau waktu yang terbatas (deadline) yang mempengaruhi kepuasan tenant.

\section{Konstelasi Penelitian Penentuan Prioritas Perbaikan Gedung}

Guna mengatasi masalah penentuan prioritas komponen gedung mall diperlukan penelitian tentang analisis penentuan prioritas untuk pengambilan keputusan. Beberapa peneliti telah mencoba mengatasi masalah tersebut melalui penelitian - penelitian seperti yang tercantum pada tabel Konstelasi Penelitian Penentuan Prioritas Perbaikan Gedung (Lihat Tabel 1).

Saparudin, dkk melakukan penelitian tentang perbaikan gedung Kecamatan di Kabupaten Jember menggunakan metode Analytical Hierarchy Proccess (AHP). Hartono, dan Ratnaningsih (2017) melakukan penelitian tentang Penentuan Prioritas Pemeliharaan dan Pengembangan 


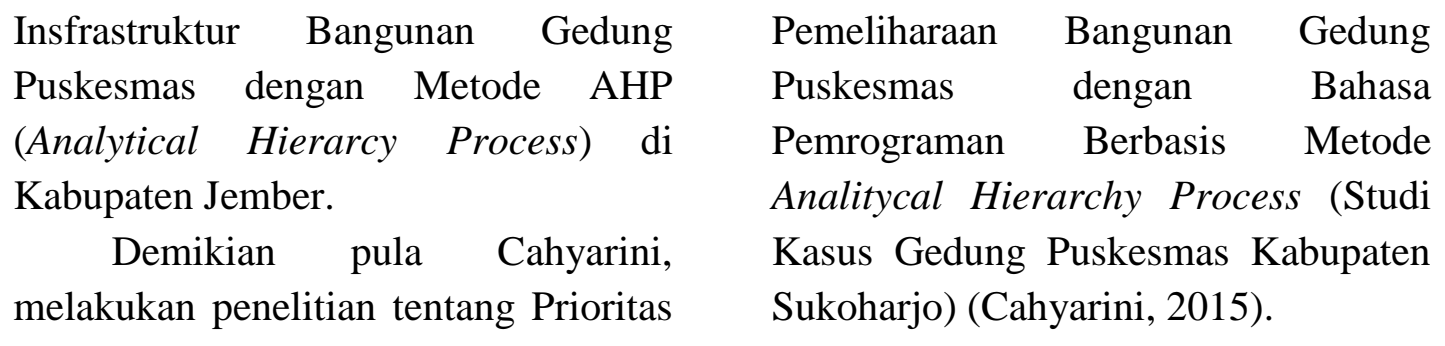

Tabel 1. Konstelasi Penelitian Skala Prioritas Menggunakan AHP

\begin{tabular}{|c|c|c|c|c|}
\hline No & Peneliti dan Judul & Pendekatan & Persamaan & Perbedaan \\
\hline 1. & $\begin{array}{l}\text { Saparudin, dkk } \\
\text { (2017) "Skala Prioritas } \\
\text { Pemeliharaan Gedung - } \\
\text { Gedung Kantor Kecamatan } \\
\text { di Kabupaten Sukoharjo } \\
\text { dengan Metode Analytical } \\
\text { Hierarchy Process (AHP)" }\end{array}$ & $\begin{array}{l}\text { Analytical } \\
\text { Hierarchy } \\
\text { Process (AHP) }\end{array}$ & $\begin{array}{l}\text { Menentukan skala } \\
\text { prioritas } \\
\text { pemeliharaan } \\
\text { gedung dengan } \\
\text { menggunakan } \\
\text { Metode Analytical } \\
\text { Hierarchy Process } \\
\text { (AHP) }\end{array}$ & $\begin{array}{l}\text { Penelitian ini } \\
\text { dilakukan di } \\
\text { gedung kantor } \\
\text { dengan luas } \\
<500 \mathrm{~m} 2 \text {, dan } \\
\text { komponen } \\
\text { bangunan yang } \\
\text { diteliti tidak } \\
\text { kompleks. }\end{array}$ \\
\hline 2. & $\begin{array}{l}\text { Hartono, dan Ratnaningsih } \\
\text { (2017) "Penentuan Prioritas } \\
\text { Pemeliharaan Dan } \\
\text { Pengembangan } \\
\text { Insfrastruktur Bangunan } \\
\text { Gedung Puskesmas Dengan } \\
\text { Metode } \\
\text { AHP (Analytical Hierarcy } \\
\text { Process) } \\
\text { di Kabupaten Jember" }\end{array}$ & $\begin{array}{l}\text { Analytical } \\
\text { Hierarchy } \\
\text { Process (AHP) }\end{array}$ & $\begin{array}{l}\text { Menentukan skala } \\
\text { pemeliharaan } \\
\text { bangunan } \\
\text { menggunakan } \\
\text { Metode Analytical } \\
\text { Hierarchy Process } \\
\text { (AHP) }\end{array}$ & $\begin{array}{l}\text { Penelitian } \\
\text { dilakukan untuk } \\
\text { menentukan } \\
\text { prioritas } \\
\text { pemeliharaan } \\
\text { dan } \\
\text { pengembangan } \\
\text { insfrastuktur } \\
\text { gedung } \\
\text { puskesmas } \\
\end{array}$ \\
\hline 3. & $\begin{array}{l}\text { Cahyarini (2015) "Prioritas } \\
\text { Pemeliharaan Bangunan } \\
\text { Gedung Puskesmas dengan } \\
\text { Bahasa Pemprograman } \\
\text { Berbasis Metode Analytical } \\
\text { Hierarchy Process (Studi } \\
\text { Kasus Gedung Puskesmas } \\
\text { Kabupaten Sukoharjo)" }\end{array}$ & $\begin{array}{l}\text { Analytical } \\
\text { Hierarchy } \\
\text { Process (AHP) }\end{array}$ & $\begin{array}{l}\text { Meneliti komponen } \\
\text { bangunan dengan } \\
\text { metode Analytical } \\
\text { Hierarchy Process } \\
\text { (AHP) }\end{array}$ & $\begin{array}{l}\text { Penelitian ini } \\
\text { dilakukan di } \\
\text { gedung } \\
\text { puskesmas } \\
\text { dengan luas dan } \\
\text { kapasitas yang } \\
\text { kecil dan } \\
\text { komponen } \\
\text { bangunan yang } \\
\text { tidak kompleks } \\
\end{array}$ \\
\hline 4. & $\begin{array}{l}\text { Putra, D dan Rianto, F } \\
\text { (2018) "Penentuan Skala } \\
\text { Prioritas Pemeliharaan } \\
\text { Gedung Perkantoran C } \\
\text { L2DIKTI Wilayah VI Jawa } \\
\text { Tengah dengan Metode } \\
\text { Analytical Hierarchy } \\
\text { Process (AHP)" }\end{array}$ & $\begin{array}{l}\text { Analytical } \\
\text { Hierarchy } \\
\text { Process (AHP) }\end{array}$ & $\begin{array}{l}\text { Mengkaji prioritas } \\
\text { pemeliharaan } \\
\text { menggunakan } \\
\text { metode Analytical } \\
\text { Hierarchy Process } \\
\text { (AHP) }\end{array}$ & $\begin{array}{l}\text { Objek yang } \\
\text { diteliti gedung } \\
\text { kantor bukan } \\
\text { gedung komersil } \\
\text { sehingga } \\
\text { komponen dan } \\
\text { kerusakan tidak } \\
\text { kompleks } \\
\end{array}$ \\
\hline 5. & $\begin{array}{l}\text { Ma'shum, F dan } \\
\text { Dharmawan, H } \\
\text { (2018) “Analisa Prioritas } \\
\text { Pemeliharaan Gedung PT. } \\
\text { Telkom Regional IV Jateng } \\
\text { \& DIY Menggunakan } \\
\text { Metode Analytical } \\
\text { Hierarchy Process (AHP)” }\end{array}$ & $\begin{array}{l}\text { Analytical } \\
\text { Hierarchy } \\
\text { Process (AHP) }\end{array}$ & $\begin{array}{l}\text { Menentukan } \\
\text { prioritas } \\
\text { pemeliharaan } \\
\text { menggunakan } \\
\text { metode Analytical } \\
\text { Hierarchy Process } \\
\text { (AHP) }\end{array}$ & $\begin{array}{l}\text { Objek yang } \\
\text { diteliti gedung } \\
\text { kantor sehingga } \\
\text { responden yang } \\
\text { terkait adalah } \\
\text { karyawan, dan } \\
\text { pihak PT. } \\
\text { Telkom Regional }\end{array}$ \\
\hline
\end{tabular}




\begin{tabular}{|c|c|c|c|c|}
\hline & & & & $\begin{array}{l}\text { IV Jateng dan } \\
\text { DIY }\end{array}$ \\
\hline 6. & $\begin{array}{l}\text { Stefanus, S. dkk. (2019) } \\
\text { "Penentuan Prioritas } \\
\text { Perbaikan Gedung dengan } \\
\text { Metode Analytical } \\
\text { Hierarchy Process (AHP)" }\end{array}$ & $\begin{array}{l}\text { Analytical } \\
\text { Hierarchy } \\
\text { Process (AHP) }\end{array}$ & $\begin{array}{l}\text { Menentukan } \\
\text { prioritas perbaikan } \\
\text { gedung } \\
\text { menggunakan } \\
\text { metode Analytical } \\
\text { Hierarchy Process } \\
\text { (AHP) }\end{array}$ & $\begin{array}{l}\text { Penelitian } \\
\text { dilakukan pada } \\
\text { gedung komersil } \\
\text { yaitu Paragon } \\
\text { Mall Semarang } \\
\text { dengan } \\
\text { responden } \\
\text { tenant. }\end{array}$ \\
\hline
\end{tabular}

$\begin{array}{ccr}\text { Putra, D } & \text { dan Rianto, F } & \text { (2018) } \\ \text { melakukan } & \text { penelitian } & \text { tentang } \\ \text { Penentuan } & \text { Skala } & \text { Prioritas }\end{array}$

Pemeliharaan Gedung Perkantoran C L2DIKTI Wilayah VI Jawa Tengah dengan Metode Analytical Hierarchy Process (AHP). Ma'shum, F dkk (2018) meneliti tentang Prioritas Pemeliharaan Gedung PT. Telkom Regional IV Jateng \& DIY menggunakan Metode Analytical Hierarchy Process (AHP), yaitu pada gedung kantor dengan jumlah lantai < 2 lantai.

Kelemahan dari penelitianpenelitian tersebut adalah pada objek penelitian yang mempunyai skala dan kapasitas kecil, yakni gedung kantor atau puskesmas. Sehingga komponen bangunan yang ada tidak terlalu kompleks. Dari segi kepuasan penghuni, penelitian tersebut hanya untuk menunjang kenyamanan karyawan dan pengunjung kantor atau puskesmas yang relatif kecil, sehingga pengambilan keputusan terkait prioritas perbaikan tidak terlalu kompleks.

Selain itu penelitian- penelitian tersebut menunjukkan bahwa Metode Analytical Hierarchy Proccess (AHP) sebagai salah satu pendekatan dapat digunakan untuk menemukan solusi atas masalah- masalah yang tidak terstruktur dan kompleks melalui penyusunan hirarkhi yang akan memudahkan pengambilan keputusan.

Metode AHP bila diterapkan dalam pengambilan keputusan, akan membantu seseorang untuk menggambarkan operasi pengambilan keputusan secara umum dengan menguraikan masalah yang kompleks menjadi struktur hierarki tujuan, kriteria, subkriteria, dan alternatif yang bertingkat (Saaty, 1990). Penelitian ini merupakan bagian dari roadmap penelitian prioritas pemeliharaan dan perbaikan gedung dari sudut pandang tenant, pengunjung, dan staf. Khusus penelitian ini dibatasi hanya pada aspek prioritas perbaikan gedung dari sudut pandang tenant saja.

Responden dari pihak tenant Paragon Mall Semarang. Objek yang diteliti meliputi komponen yang berkaitan dengan tenant beserta kerusakan yang terjadi pada komponen tersebut.

\section{Pengembangan Model Pengambilan Keputusan Prioritas Perbaikan Gedung}

Pengembangan model pengambilan keputusan perlu diawali dengan pemahaman keseluruhan komponen bangunan dan kondisinya. 
Penentuan kondisi komponen jumlah perkalian antara nilai bangunan dilakukan dengan pengurang dengan faktor koreksi melakukan survey langsung terhadap adalah seratus. Nilai index kondisi komponen yang telah ditentukan untuk gabungan dapat digunakan sebagai dilakukan penelitian. Survey dilaksanakan dengan tim teknisi dari Paragon Mall Semarang. dasar dalam penanganan bangunan seperti yang diperlihatkan dalam Tabel 2.

Untuk semua jenis kerusakan pada satu sub elemen, maksimum

Tabel 2. Skala Index Kondisi Bangunan

\begin{tabular}{|c|c|c|c|c|}
\hline $\begin{array}{c}\text { Zon } \\
\text { e }\end{array}$ & $\begin{array}{l}\text { Index } \\
\text { Kondis } \\
\quad \mathrm{i}\end{array}$ & $\begin{array}{l}\text { Kriteria } \\
\text { Kondisi }\end{array}$ & Uraian kondisi & Tindakan Penanganan \\
\hline \multirow[b]{2}{*}{1} & $85-100$ & Baik sekali & $\begin{array}{l}\text { Tidak terlihat kerusakan, beberapa } \\
\text { kekurangan mungkin terlihat }\end{array}$ & \multirow{2}{*}{$\begin{array}{l}\text { Tindakan segera } \\
\text { masih belum } \\
\text { diperlukan }\end{array}$} \\
\hline & $70-84$ & Baik & $\begin{array}{l}\text { Hanya terjadi deteriorasi atau } \\
\text { kerusakankecil }\end{array}$ & \\
\hline \multirow[t]{2}{*}{2} & $55-69$ & Sedang & $\begin{array}{l}\text { Mulai terjadi deteriorasi atau } \\
\text { kerusakan namun tidak } \\
\text { mempengaruhi fungsi struktur } \\
\text { bangunan secara keseluruhan }\end{array}$ & \multirow{2}{*}{$\begin{array}{l}\text { Perlu dibuat analisis } \\
\text { ekonomi alternatif } \\
\text { perbaikan untuk } \\
\text { menetapkan tindakan } \\
\text { yang sesuai/tepat }\end{array}$} \\
\hline & $40-54$ & Cukup & $\begin{array}{l}\text { Terjadi deteriorasi atau kerusakan } \\
\text { tetapi bangunan masih cukup } \\
\text { berfungsi }\end{array}$ & \\
\hline \multirow{3}{*}{3} & $25-39$ & Buruk & $\begin{array}{l}\text { Terjadi kerusakan yang cukup } \\
\text { kritis sehingga fungsi bangunan } \\
\text { terganggu }\end{array}$ & Evaluasi secara detail \\
\hline & $10-24$ & $\begin{array}{l}\text { Sangat } \\
\text { buruk }\end{array}$ & $\begin{array}{l}\text { Kerusakan parah dan bangunan } \\
\text { hampir tidak berfungsi }\end{array}$ & \multirow{2}{*}{$\begin{array}{l}\text { Diperlukan untuk } \\
\text { menentukan tindakan } \\
\text { repair, rehabilitasi dan } \\
\text { rekontruksi untuk } \\
\text { keamanan }\end{array}$} \\
\hline & $0-9$ & Runtuh & $\begin{array}{l}\text { Pada komponen utama bangunan } \\
\text { terjadi keruntuhan }\end{array}$ & \\
\hline
\end{tabular}

Masalah yang ada yang bersifat multi kriteria yang kompleks perlu disusun menjadi suatu hierarki. Hierarki didefinisikan sebagai suatu representasi dari sebuah permasalahan yang kompleks dalam suatu struktur multi level yang terdiri dari level pertama adalah tujuan, yang diikuti level faktor, kriteria, sub kriteria, dan seterusnya ke bawah hingga level terakhir dari alternatif.

Langkah-langkah dalam penyusunan hierarki AHP adalah sebagai berikut:
1. Mendefinisikan masalah dan menentukan solusi yang diinginkan.

2. Membuat struktur hierarki yang diawali dengan tujuan utama, kemudian menyusun level hierarki yang berada di bawahnya yaitu kriteria-kriteria yang cocok untuk mempertimbangkan atau menilai alternatif yang diberikan dan menentukan alternatif tersebut.

3. Membuat matrik perbandingan berpasangan yang menggambarkan kontribusi relatif atau pengaruh 
setiap elemen terhadap tujuan atau kriteria yang setingkat di atasnya. Perbandingan dilakukan berdasarkan judgment dari pengambil keputusan dengan menilai tingkat kepentingan suatu elemen dibandingkan elemen lainnya.

4. Melakukan perbandingan berpasangan sehingga diperoleh judgement seluruhnya sebanyak $\mathrm{n} \times$ [(n-1)/2] buah, dengan $\mathrm{n}$ adalah banyaknya elemen yang dibandingkan. Hasil perbandingan dari masing- masing elemen akan berupa angka dari 1 sampai 9 yang menunjukkan perbandingan tingkat kepentingan suatu elemen.

5. Menghitung nilai eigen dan menguji konsistensinya, jika tidak konsisten maka pengambilan data diulang kembali.

6. Mengulangi langkah 3,4, dan 5 untuk seluruh tingkat hierarki.

7. Menghitung eigen vector dari setiap matriks perbandingan berpasangan. Nilai eigen merupakan bobot setiap elemen. Langkah ini dilakukan sebagai penentuan prioritas elemen-elemen pada tingkat hierarki terendah sampai mencapai tujuan.

8. Memeriksa konsistensi hierarki yang diukur dalam AHP melalui rasio konsistensi dengan melihat index konsistensi. Concistensy Index dan Concistency Ratio dalam penilaian perbandingan berpasangan sering terjadi ketidakkonsistenan dari pendapat/ preferensi yang diberikan oleh pengambil keputusan. Konsistensi dari penilaian berpasangan tersebut dievaluasi dengan menghitung Consistency Ratio (CR). Saaty menetapkan apabila $\mathrm{CR} \leq 0,1$, maka hasil penilaian tersebut dikatakan konsisten. Apabila Nilai Rasio Konsistensi > 0,1 maka penilaian perbandingan harus dilakukan kembali. Formulasi untuk menghitung $\mathrm{CR}$ adalah:

$\mathrm{CR}=\mathrm{CI} / \mathrm{R} \ldots$

Keterangan:

$\mathrm{CI}=$ Consistency Index (Index

Konsistensi)

$\mathrm{RI}=$ Random

$C I=\frac{(\lambda \max -n)}{(n-1)}$

Keterangan:

$\mathrm{CI}=$ Index konsistensi

$\Lambda$ maks $=$ eigen value maksimum

$\mathrm{n}$ = banyaknya elemen yang digunakan.

Eigen value maksimum didapat dengan menjumlahkan hasil perkalian matriks perbandingan dengan eigen vector utama (vektor prioritas) dan membaginya dengan jumlah elemen. Nilai CI tidak akan berarti bila tidak terdapat acuan untuk menyatakan apakah CI menunjukkan suatu matriks yang konsisten atau tidak konsisten? Nilai rata-rata Random Index (RI) seperti pada Tabel 3 berikut: 
Tabel 3. Tabel Nilai Random Index (RI)

\begin{tabular}{lccccccccccccccc}
\hline Ukuran Matriks & 1 & 2 & 3 & 4 & 5 & 6 & 7 & 8 & 9 & 10 & 11 & 12 & 13 & 14 & 15 \\
\hline Vilai RI & 0 & 0 & 0,58 & 0,90 & 1,12 & 1,24 & $1,321,41$ & $1,451,491,511,481,56$ & 1,57 & 1,59 \\
\hline
\end{tabular}

Nilai eigen suatu matriks tidak akan lebih kecil dari nilai $\mathrm{n}$ sehingga, tidak mungkin jika CI bernilai negatif.
Skala Penilaian Perbandingan Berpasangan dapat dilihat pada Tabel 4.

Tabel 4. Skala Penilaian Perbandingan Berpasangan

\begin{tabular}{|c|c|c|}
\hline Skala & Definisi & Keterangan permisalan \\
\hline 1 & $\begin{array}{l}\text { Tingkat kepentingan yang } \\
\text { sama }\end{array}$ & Elemen 1 dan 2 sama pentingnya \\
\hline 3 & $\begin{array}{l}\text { Tingkat kepentingan cukup } \\
\text { penting }\end{array}$ & Elemen 1 cukup penting dibandingkan elemen 2 \\
\hline 5 & $\begin{array}{l}\text { Tingkat kepentingan lebih } \\
\text { penting }\end{array}$ & Elemen 1 lebih penting dibandingkan elemen 2 \\
\hline 7 & $\begin{array}{l}\text { Tingkat kepentingan sangat } \\
\text { lebih penting }\end{array}$ & $\begin{array}{lcc}\text { Elemen } 1 \text { sangat } & \text { lebih penting } \\
\text { dibandingkan elemen } 2 . & \\
\end{array}$ \\
\hline 9 & $\begin{array}{l}\text { Tingkat kepentingan mutlak } \\
\text { lebih penting }\end{array}$ & $\begin{array}{l}\text { Elemen } 1 \text { mutlak pentingnya } \\
\text { dibandingkan elemen } 2 .\end{array}$ \\
\hline $2,4,6,8$ & Nilai-nilai antara & $\begin{array}{l}\text { Jika ragu-ragu dalam memilih skala, misalkan } \\
\text { memilih sedikit lebih penting yaitu antara sama } \\
\text { penting atau lebih cukup penting (nilai } 2 \text { ). }\end{array}$ \\
\hline Resprokal & $\begin{array}{l}\text { Jika elemen } 1 \text { dibanding } \\
\text { elemen } 2 \text { adalah skala } 7, \\
\text { maka elemen } 2 \text { dibanding } \\
\text { elemen } 1 \text { adalah skala } 1 / 7\end{array}$ & Asumsi yang masuk akal \\
\hline
\end{tabular}

(Sumber: Saaty, 1990)

\section{Aspek-aspek yang Mempengaruhi Prioritas Perbaikan}

Prioritas Perbaikan Gedung Paragon Mall Semarang ini mempertimbangkan prioritas perbaikan komponen dalam risiko yang timbul dari aspek kenyamanan, lingkungan (Marsha, 2015), fasilitas dan kemudahan parkir (Subagio, 2011), dana atau biaya yang terbatas, SDM/ petugas yang terbatas serta waktu yang terbatas (deadline) (Indra, dkk, 2016). Berdasarkan Persyaratan Keandalan bangunan yang tercantum dalam Undang-Undang No. 28 Tahun 2002, bahwa prioritas perbaikan bangunan gedung meliputi komponen kenyamanan, kesehatan, keselamatan, dan kemudahan akses. Oleh sebab itu perlu dilakukan analisis perbaikan gedung yang melibatkan aspek kenyamanan, kesehatan, keselamatan, kemudahan akses, dana/ biaya terbatas, jadwal petugas yang terbatas dan waktu yang terbatas (deadline).

Menurut Permen PU No 24 tahun 2008 tentang pedoman pemeliharaan dan perbaikan bangunan gedung, bahwa gedung terdiri dari beberapa komponen. Komponen tersebut diantaranya adalah komponen Arsitektur, Struktur, Mekanikal, Elektrikal, Tata Graha (House Keeping), dan Tata Ruang Luar. 
Komponen-komponen tersebut meliputi aspek sarana sirkulasi (koridor, tangga, lift, eskalator), interior (dinding, partisi, lantai, plafond, etalase), struktur (kolom, balok, lantai, atap), sistem tata udara (ventilasi dan AC), sistem kelistrikan dan penerangan, sistem tata suara (speaker dan amplifier), jaringan telepon dan komputer/internet, tatagraha (hygene dan cleaning service), dan fasilitas parkir dan jalan akses.

Berdasarkan uraian tersebut maka dapat disusun model hierarkhi untuk penngambilan keputusan dengan Kriteria dan Alternatif seperti gambar

berikut ini. Model ini kemudian diuji melalui kuesioner untuk tenant berdasarkan komponen-komponen tersebut dan dianalisis dengan metode Analytical Hierarchy Process (AHP).

Dari hasil analisis akan diperoleh skala prioritas perbaikan gedung pada setiap aspek Kriteria dan Alternatif untuk pengambilan keputusan perbaikan gedung bila dihadapkan pada tuntutan/ kondisi yang kompleks, misalnya dana/ petugas yang terbatas atau tuntutan aspek kenyamanan, kesehatan, dan sebagainya.

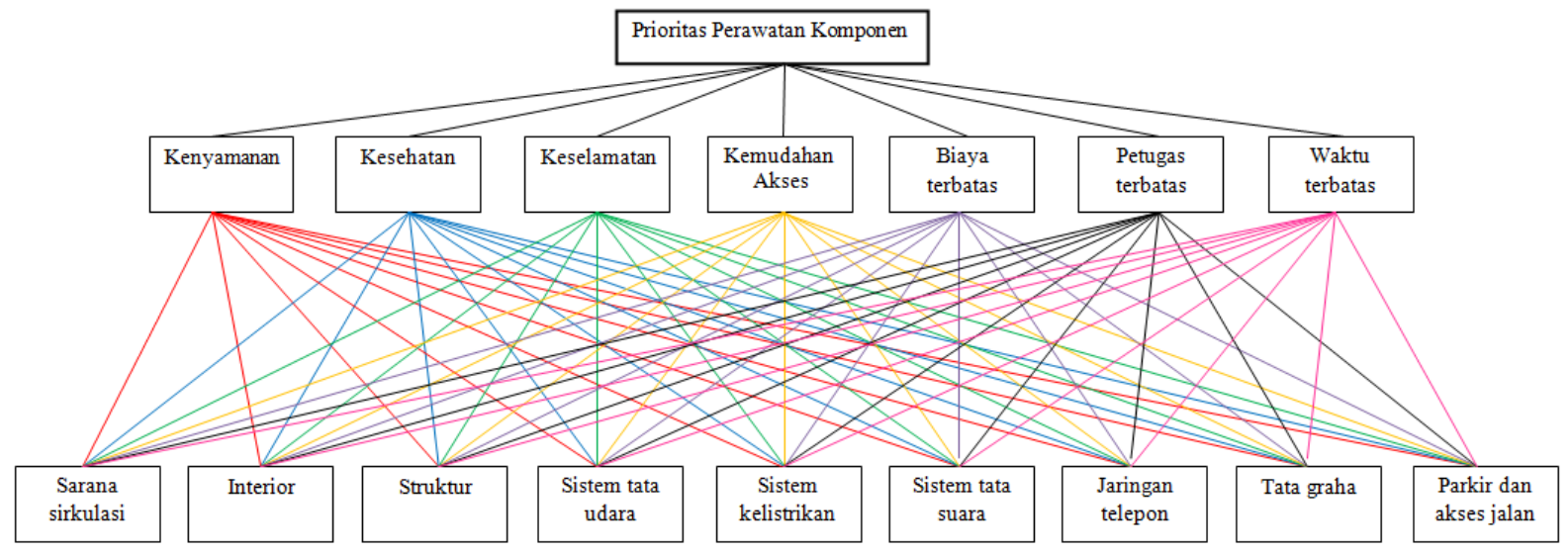

Gambar 1. Susunan Hierarki Kriteria dan Alternatif Prioritas Perbaikan Komponen Bangunan

\section{METODE PENELITIAN}

\section{Assesement Kondisi Bangunan}

Paragon Mall Semarang mempunyai sekitar 120 tenant yang tersebar dari lantai LG hingga lantai 3. Setiap tenant mempunyai komponen bangunan utama seperti instalasi air bersih dan air kotor, instalasi listrik, penerangan, speaker, AC, dan telepon. Tenant dibatasi oleh dinding partisi dari gypsum untuk membatasi ruang produktivitas.

\section{Pengumpulan Data}

Pada penelitian ini, lokasi yang digunakan adalah Paragon Mall Semarang beralamat di jalan Pemuda No 118, Sekayu, Semarang Tengah, Kota Semarang, Jawa Tengan 50132.

Form kuesioner disusun berdasarkan model yang telah disusun 
yang terdiri dari komponen arsitektur (dinding, partisi, plafond, dan etalase), mekanikal (koridor, tangga, lift, eskalator, ventilasi dan AC), struktur (kolom, balok, lantai, dan atap), elektrikal (sistem kelistrikan dan penerangan, sistem tata suara, jaringan telepon dan komputer atau internet), tata graha (hygene dan cleaning service) dan tata luar ruang (fasilitas parkir dan jalan akses), dengan mempertimbangkan aspek kenyamanan, kesehatan, keselamatan, kemudahan akses, dana atau biaya yang terbatas, jadwal petugas yang padat, dan waktu yang terbatas.

\section{Rekapitulasi Data}

Berdasarkan sumbernya, maka data penelitian yang dipakai dikelompokkan menjadi 2 (dua) jenis yaitu data primer yang diperoleh melalui survei lapangan dan form kuesioner serta data sekunder yang diperoleh dari berbagai referensi/ sumber mencakup lokasi bangunan, informasi-informasi mengenai letak geografis bangunan, data lain yang menunjang. Data hasil kuesioner diperiksa kelengkapannya dan disortir bila ada data yang rusak atau tidak memenuhi syarat (melanggar aturan pengisian form kuesioner) sehingga data tidak dapat dianalisis. Dari total 40 kuesioner yang dibagikan, 30 kuesioner sesuai dengan petunjuk pengisian, dan 10 kuesioner tidak sesuai petunjuk pengisian.

\section{Analisis Data Perbaikan Bangunan}

Data dari responden digunakan untuk menentukan penilaian pembobotan antar-kriteria sehingga membantu dalam menentukan skala prioritas perbaikan gedung dengan menggunakan metode Analytical Hierarchy Process (AHP) dan bantuan software Excel untuk mengolah data.

\section{Penyusunan Matrik Pairwise Comparison}

Matrik Pairwise Comparison (Tabel 5) disusun berdasarkan penilaian perbandingan dari kriteria. Perbandingan ditentukan dengan mengamati kebijakan yang dianut oleh penilai yang diperoleh dari kuesioner, ceklis, atau basis data. Perbandingan di atas adalah dengan membandingkan kolom yang terletak paling kiri dengan setiap kolom kedua, ketiga, hingga ke sembilan.

\section{Menentukan Rangking Kriteria}

Penentuan rangking kriteria dalam bentuk vektor prioritas (disebut juga eigen vector ternormalisasi) dengan cara mengubah matriks Pairwise Comparison ke bentuk desimal dan menjumlahkan nilai tiap kolom.

\section{Menentukan Consistency Ratio (CR)}

Dalam melakukan analisis metode Analytical Hierarchy Process (AHP), diperlukan tahap pengujian konsistensi. Apabila Consistency Ratio $(\mathrm{CR})>0.1$ atau $\mathrm{CR}>10 \%$, maka konsistensi tidak terpenuhi dan pengambilan data diulang kembali. Sebaliknya, apabila Consistency Ratio $(\mathrm{CR})<0,1$, maka data dapat diterima (Saaty,1990). 
Tabel 5. Matrik Pairwise Comparison untuk Alternatif

\begin{tabular}{|c|c|c|c|c|c|c|c|c|c|}
\hline Alternatif & $\begin{array}{c}\text { Sarana } \\
\text { Sirkula } \\
\text { si }\end{array}$ & Interior & $\begin{array}{c}\text { Struktu } \\
\mathrm{r} \\
\text { Gedung }\end{array}$ & $\begin{array}{c}\text { Siste } \\
\mathrm{m} \\
\text { Tata } \\
\text { Udara }\end{array}$ & $\begin{array}{c}\text { Siste } \\
\mathrm{m} \\
\text { Kelis } \\
\text { trikan }\end{array}$ & $\begin{array}{c}\text { Siste } \\
\mathrm{m} \\
\text { Tata } \\
\text { Suara }\end{array}$ & $\begin{array}{c}\text { Jaringan } \\
\text { Telepon } \\
\& \\
\text { komputer }\end{array}$ & $\begin{array}{c}\text { Tata } \\
\text { Graha }\end{array}$ & $\begin{array}{c}\text { Parkir } \\
\text { dan } \\
\text { Akses } \\
\text { Jalan }\end{array}$ \\
\hline Sarana Sirkulasi & 1,000 & & & & & & & & \\
\hline Interior & & 1,000 & & & & & & & \\
\hline Struktur Gedung & & & 1,000 & & & & & & \\
\hline Sistem Tata Udara & & & & 1,000 & & & & & \\
\hline Sistem Kelistrikan & & & & & 1,000 & & & & \\
\hline Sistem Tata Suara & & & & & & 1,000 & & & \\
\hline $\begin{array}{c}\text { Jaringan Telepon \& } \\
\text { komputer }\end{array}$ & & & & & & 1,000 & & \\
\hline Tata Graha & & & & & & & & & \\
\hline $\begin{array}{c}\text { Parkir dan Akses } \\
\text { Jalan }\end{array}$ & & & & & & & & 1,000 \\
\hline
\end{tabular}

(Sumber Acuan Data Primer, 2019)

\section{Menentukan Rangking Alternatif}

Rangking alternatif ditentukan dengan cara menghitung eigen vector untuk tiap kriteria dan subkriteria. Nilai bobot diperoleh dari kondisi yang dimiliki oleh alternatif. Hasil diperoleh dari perkalian nilai vector kriteria dengan vector subkriteria dan setiap hasil perkalian kriteria dan subkriteria masing-masing kolom dijumlahkan.

\section{Pengambilan Kesimpulan}

Penentuan prioritas penanganan perbaikan gedung Paragon Mall Semarang berdasarkan nilai setiap aspek Kriteria maupun Alternatif yang diperoleh guna Pengambilan Keputusan Perbaikan Gedung dengan mempertimbangkan

faktor

Kenyamanan, Kesehatan,

Keselamatan, Kemudahan Akses, Dana/Biaya yang Terbatas, Petugas yang Terbatas dan Waktu yang Terbatas (deadline) baik secara parsial maupun gabungan.

\section{HASIL DAN PEMBAHASAN}

Berdasarkan analisis yang telah dilakukan, diperoleh urutan prioritas berdasarkan komponen bangunan sebagai alternatif perbaikan Paragon Mall dengan mempertimbangkan faktor kenyamanan, kesehatan, keselamatan, kemudahan akses, dana/biaya yang terbatas, jadwal petugas yang padat dan waktu yang terbatas (Deadline) seperti tercantum dalam tabel 6.

Tabel 6 merupakan tabel rangking perbaikan Gedung Paragon Mall Semarang berdasarkan nilai bobot (\%). Baris horizontal merupakan bobot setiap alternatif dari komponen bangunan yang perlu diprioritaskan dalam perbaikan. Warna latar belakang coklat/ gelap menunjukkan rangking tertinggi sedangkan warna kuning/ agak terang menunjukkan rangking terendah. Kolom merupakan alternatif yang bisa dipilih sesuai bobot masingmasing dalam melakukan perbaikan pada Gedung Paragon Mall Semarang. 
Tabel 6. Rangking Prioritas Perbaikan Gedung Paragon Mall Semarang dalam

\begin{tabular}{|c|c|c|c|c|c|c|c|c|c|}
\hline \multicolumn{10}{|c|}{ Bobot $(\%)$} \\
\hline $\begin{array}{l}\text { Alternatif/Kri } \\
\text { teria }\end{array}$ & $\begin{array}{c}\text { Sarana } \\
\text { Sirkulasi }\end{array}$ & Interior & $\begin{array}{l}\text { Struktur } \\
\text { Gedung }\end{array}$ & $\begin{array}{c}\text { Sistem } \\
\text { Tata } \\
\text { Udara }\end{array}$ & $\begin{array}{c}\text { Sistem } \\
\text { Kelistrikan }\end{array}$ & $\begin{array}{c}\text { Sistem } \\
\text { Tata } \\
\text { Suara }\end{array}$ & $\begin{array}{c}\text { Jaringan } \\
\text { Telepon } \\
\text { dan } \\
\text { komputer }\end{array}$ & $\begin{array}{l}\text { Tata } \\
\text { Graha }\end{array}$ & $\begin{array}{c}\text { Parkir } \\
\text { dan } \\
\text { Jalan } \\
\text { Akses }\end{array}$ \\
\hline Kenyamanan & 20,191 & 12,135 & 6,883 & 15,345 & 10,655 & 6,682 & 5,384 & 14,808 & 15,524 \\
\hline Kesehatan & 18,713 & 11,475 & 5,937 & 14,154 & 10,269 & 8,221 & 5,531 & 23,580 & 15,273 \\
\hline Keselamatan & 23,959 & 13,179 & 8,090 & 7,739 & 13,817 & 10,152 & 6,227 & 12,309 & 19,673 \\
\hline $\begin{array}{c}\text { Kemudahan } \\
\text { Akses }\end{array}$ & 21,404 & 11,196 & 8,229 & 6,625 & 15,78 & 10,733 & 8,003 & 11,512 & 19,116 \\
\hline $\begin{array}{c}\text { Biaya } \\
\text { Terbatas }\end{array}$ & 17,181 & 20,732 & 8,665 & 13,906 & 10,944 & 7,928 & 4,256 & 11,753 & 11,399 \\
\hline $\begin{array}{l}\text { Petugas } \\
\text { Terbatas }\end{array}$ & 17,792 & 20,77 & 8,476 & 15,753 & 11,513 & 6,688 & 6,535 & 11,742 & 11,758 \\
\hline $\begin{array}{c}\text { Waktu } \\
\text { Terbatas }\end{array}$ & 21,536 & 18,763 & 9,788 & 14,38 & 10,81 & 7,653 & 4,54 & 10,791 & 11,947 \\
\hline
\end{tabular}

(Sumber: Data Primer yang Diolah, 2019)

Berdasarkan Tabel 6, jika terjadi biaya terbatas dan waktu terbatas, maka alternatif yang harus didahulukan adalah Interior dan sirkulasi karena mempunyai bobot paling besar, dan yang tidak terlalu penting adalah jaringan telepon dan komputer karena mempunyai bobot paling rendah. Jika faktor Kenyamanan dan Kesehatan yang menjadi pertimbangan utama, maka alternatif yang didahulukan adalah sarana sirkulasi dan tata graha, sedangkan yang tidak terlalu penting adalah jaringan telepon dan komputer dengan bobot paling rendah.

Prioritas yang diperoleh tercantum pada poin-poin berikut ini.

1. Bila faktor Kenyamanan menjadi pertimbangan utama, maka prioritas perbaikan peringkat pertama adalah sarana sirkulasi (koridor, tangga, lift, eskalator) dengan nilai prioritas perbaikan 20,191\%, peringkat kedua fasilitas parkir dan jalan akses dengan nilai prioritas perbaikan $15,524 \%$, dan peringkat ketiga sistem tata udara (ventilasi dan AC) dengan nilai prioritas perbaikan 15,354\%.

2. Bila faktor Kesehatan menjadi pertimbangan utama, maka prioritas perbaikan peringkat pertama adalah tata graha dan hygene \& cleaning service dengan nilai prioritas perbaikan 23,580\%, peringkat kedua sarana sirkulasi (koridor, tangga, lift, eskalator) dengan nilai prioritas perbaikan $18,713 \%$, dan peringkat ketiga fasilitas parkir dan jalan akses dengan nilai prioritas perbaikan $15,273 \%$.

3. Bila faktor Keselamatan menjadi pertimbangan utama, maka prioritas perbaikan peringkat pertama adalah sarana sirkulasi (koridor, tangga, lift, eskalator) dengan nilai prioritas perbaikan 23,959\%, peringkat kedua fasilitas parkir dan jalan akses dengan nilai prioritas perbaikan 19,673\%, dan peringkat ketiga sistem kelistrikan dan 
penerangan dengan nilai prioritas perbaikan $13,817 \%$.

4. Bila faktor Kemudahan Akses menjadi pertimbangan utama, maka prioritas perbaikan peringkat pertama adalah sarana sirkulasi (koridor, tangga, lift, eskalator) dengan nilai prioritas perbaikan $21,404 \%$, peringkat kedua fasilitas parkir dan jalan akses dengan nilai prioritas perbaikan $19,116 \%$, dan peringkat ketiga sistem kelistrikan dan penerangan dengan nilai prioritas perbaikan $15,780 \%$.

5. Bila faktor Dana/ Biaya yang Terbatas menjadi pertimbangan utama, maka prioritas perbaikan peringkat pertama adalah interior (dinding, partisi, lantai, plafond, etalase) dengan nilai prioritas perbaikan $20,732 \%$, peringkat kedua sarana sirkulasi (koridor, tangga, lift, eskalator) dengan nilai prioritas perbaikan $17,181 \%$, dan peringkat ketiga sistem tata udara (ventilasi, AC) dengan nilai prioritas perbaikan $13,906 \%$.

6. Bila faktor Petugas yang Terbatas menjadi pertimbangan utama, maka prioritas perbaikan peringkat pertama adalah interior (dinding, partisi, lantai, plafond, etalase) dengan nilai prioritas perbaikan $20,770 \%$, peringkat kedua sarana sirkulasi (koridor, tangga, lift, eskalator) dengan nilai prioritas perbaikan $17,792 \%$, dan peringkat ketiga sistem tata udara (ventilasi, AC) dengan nilai prioritas perbaikan $15,753 \%$.

7. Bila faktor Waktu yang Terbatas (deadline) menjadi pertimbangan utama, maka prioritas perbaikan peringkat pertama adalah sirkulasi (koridor, tangga, lift, eskalator) dengan nilai prioritas perbaikan $21,556 \%$, peringkat kedua interior (dinding, partisi, lantai, plafond, etalase) dengan nilai prioritas perbaikan $18,763 \%$, dan peringkat ketiga sistem tata udara (ventilasi, AC) dengan nilai prioritas perbaikan 14,380\%.

Dari sudut pandang yang lebih umum dan menyeluruh, dari ketujuh faktor utama, yakni Kenyamanan, Keselamatan, Kemudahan Akses, Dana/Biaya yang Terbatas, Petugas yang Terbatas, dan Waktu yang Terbatas (deadline) dapat dilakukan analisis pula. Berikut ini dengan metode analisis yang sama diperoleh faktor- faktor yang menjadi prioritas dari sudut pandang secara global.

Tabel 7. Urutan Prioritas Perbaikan antar-Faktor- faktor Utama

\begin{tabular}{|l|c|}
\hline \multicolumn{1}{|c|}{ Kriteria } & Bobot Kriteria $(\boldsymbol{\%})$ \\
\hline Kenyamanan & 22,611 \\
\hline Keselamatan & 17,193 \\
\hline Biaya yang terbatas & 15,564 \\
\hline Kemudahan akses & 13,429 \\
\hline Kesehatan & 13,251 \\
\hline Petugas Terbatas & 7,359 \\
\hline Waktu yang terbatas & 6,798 \\
\hline
\end{tabular}

(Sumber: Data Primer yang Diolah, 2019)

Dari hasil analisis diperoleh rangking teratas yang menjadi prioritas global adalah faktor Kenyamanan dengan nilai $22,611 \%$ yang diikuti oleh faktor Keselamatan dengan nilai $17,193 \%$. Satu hal yang menarik di sini adalah 
faktor Kenyamanan dari sudut pandang tenant merupakan faktor yang paling diharapkan melebihi faktor Keamanan. Hal ini dapat dimengerti karena kemungkinan menurut padangan tenant frekuensi terjadinya hal- hal yang mengganggu Keamanan sangat rendah dibanding frekuensi terjadinya gangguan Kenyamanan. Hal ini sesuai dengan salah satu prinsip manajerial yang tidak perlu memberikan perhatian dengan proporsi sangat besar pada halhal yang jarang terjadi walaupun dengan risiko besar, namun seharusnya fokus pada faktor- faktor dengan frekuensi tinggi dengan risiko sedang.

Faktor yang memiliki priorotas rendah adalah Faktor Waktu yang Terbatas, dan Petugas yang Terbatas. Kedua faktor ini relatif lebih mudah diatasi dibanding misalnya faktor Dana yang Terbatas. Kedua faktor ini saling terkait, proses perbaikan dapat dipercepat dengan menambah petugas/ tenaga kerja, dan sebaliknya keterbatasan pekerja dapat diatasi dengan penyediaan waktu yang lebih lama.

\section{SIMPULAN}

Dari hasil analisis data maka dapat disimpulkan bahwa Model Pengambilan Keputusan Penentuan Priorias Perbaikan Gedung dengan hierarkhi yang mengandung aspek Kriteria Kenyamanan, Kesehatan, Keselamatan, Kemudahan Akses, Dana/Biaya yang Terbatas, Jadwal Petugas yang Padat, dan Waktu yang Terbatas (Deadline), dengan aspek Alternatif yang terdiri dari sarana sirkulasi (koridor, tangga, lift, eskalator), interior (dinding, partisi, lantai, plafond, etalase), struktur (kolom, balok, lantai, atap), sistem tata udara (ventilasi dan AC), sistem kelistrikan dan penerangan, sistem tata suara (speaker dan amplifier), jaringan telepon dan komputer/internet, tatagraha (hygene dan cleaning service), dan fasilitas parkir dan jalan akses, menunjukkan bahwa yang perlu menjadi perhatian utama manajemen perbaikan gedung dari sudut pandang tenant adalah sarana sirkulasi (koridor, tangga, lift, eskalator) kemudian interior dan tata-graha (hygene dan cleaning service).

Dari sisi Kriteria yang perlu memperoleh prioritas atau perhatian utama adalah faktor Kenyamanan dengan nilai 22,611 \% yang diikuti oleh faktor Keselamatan dengan nilai $17,193 \%$.

Penelitian ini terbatas pada model pengambilan keputusan prioritas perbaikan oleh pengelola gedung mall dari sudut pandang tenant (penyewa) saja, sehingga lebih mengedepankan kepentingan dan kepuasan tenant. Pengguna lain yang juga berkontribusi terhadap kesuksesan pengelolaan suatu mall adalah pengunjung mall. Oleh sebab ke depan perlu dilakukan penelitian penentuan prioritas perbaikan gedung mall dari sudut pandang dan keinginan pengunjung untuk diperbandingkan dengan keinginan tenant.

\section{UCAPAN TERIMA KASIH}

Peneliti mengucapkan terimakasih kepada Politeknik Negeri Semarang yang telah menyediakan dana dan 
fasilitas penelitian dan Pihak Manajemen Paragon Mall yang telah banyak membantu bagi terlaksananya penelitian ini.

\section{DAFTAR PUSTAKA}

Cahyarini, V.P., Hartono, W., dan Sugiyarto, 2015, Prioritas Pemeliharaan Bangunan Gedung-Gedung Puskesmas dengan Bahasa Pemograman Berbasis Metode Analytical Hierarchy Process (Studi Kasus Gedung- Gedung Puskesmas Kabupaten Sukoharjo), E-Jurnal Matriks Teknik Sipil, 2015. $1145-1150$

Hartono, M. B., dan Ratnaningsih, A., 2017, Penentuan Prioritas Pemeliharaan dan Pengembangan Insfrastruktur Bangunan Gedung Puskesmas Dengan Metode AHP (Analytical Hierarcy Process) di Kabupaten Jember. Konferensi Nasional Teknik Sipil dan Infrastruktur, Jurusan Teknik Sipil, Universitas Jember, 2017

Indra. Sinulingga, S, Nazaruddin., 2016, Analisis Efektivitas Manajemen Pemeliharaan Gedung dengan Studi Kasus Mall Meulaboh. Jurnal Ekonom, Vol 19, No 4, Oktober 2016 Ma'shum, F dan Dharmawan, H., 2018, Analisis Prioritas Pemeliharaan Gedung PT. Telkom Regional IV Jateng \& DIY Menggunakan Metode Analytical Hierarchy Process (AHP). Skripsi, Jurusan Teknik Sipil, Program Studi Teknik
Perawatan dan Perbaikan Gedung, Politeknik Negeri Semarang, 2018

Maitland, Barry, 1987, Shopping Hypermarkets Planning and Design, London, Construction Press. 1987

Marsha, A., 2015, The Impact of Plaza Indonesia Shopping Mall's Attributes toward Customers Satisfaction, iBuss Management Vol 3, No 2. 2015

Putra, D dan Rianto, F., 2018, Analisis

Skala Prioritas Pemeliharaan Gedung Perkantoran C L2DIKTs Wilayah VI Jawa Tengah dengan Metode Analytical Hierarchy Process (AHP). Skripsi, Jurusan Teknik Sipil, Program Studi Teknik Perawatan dan Perbaikan Gedung, Politeknik Negeri Semarang, 2018

Republik Indonesia, 2008, Peraturan

Menteri Pekerjaan Umum

Nomor 24/PRT/M/2008 tentang

Pedoman Pemeliharaan dan

Perawatan Bangunan Gedung.

Lembaran Negera RI Tahun

2008. Sekretariat Negara. Jakarta Republik Indonesia, 2002, Undang Undang No. 28 Tahun 2002 tentang Tujuan Pengaturan

Bangunan Gedung. Lembaran Negera RI Tahun 2002, No. 28.

Sekretariat Negara, Jakarta

Saaty, T.L., 1990, The Analytic Hieararchy Process In Conflict Management. The International Journal of Conflict Management. 1990, Vol 1, No. 1

Saparudin, Y., Hartono, W., dan Sugiyarto, 2017, Skala Prioritas 
Pemeliharaan Gedung-Gedung

Kantor Kecamatan di Kabupaten

Sukoharjo dengan Metode

Analytical Hierarchy Process

(AHP), E-Jurnal Matriks Teknik

Sipil. 2017. P.423-429

Sinchaloenman dan Ngamyan, 2013,

Key Factors Affecting Small

Tenant Decision on Renewing

Shopping mall Rent Contract.

International Journal of

Scientific and Research

Publications, Volume 3, Issue

12, December 2013, ISSN 2250-

3153

Subagio, H., 2011, Pengaruh Atribut

Supermarket terhadap Motif

Belanja Hedonik Motif Belanja

Utilitarian dan Loyalitas

Konsumen, Jurnal Manajemen

Pemasaran, Vol. 6, No. 1, April

2011: 8-21 